\title{
Regulation of angiogenesis by microRNAs in cancer
}

\author{
QI ZHENG and WEI HOU
}

Department of Oncology, Guang'anmen Hospital, China Academy of Chinese Medical Sciences, Beijing 100053, P.R. China

Received February 19, 2021; Accepted May 28, 2021

DOI: $10.3892 / \mathrm{mmr} .2021 .12222$

\begin{abstract}
MicroRNAs (miRs) are endogenous, small, non-coding RNA molecules with $\sim 22$ nucleotides, and are involved in regulating the expression of multiple genes and controlling cellular functions. miRs serve key roles in angiogenesis by regulating the proliferation, differentiation, apoptosis and migration of endothelial cells. Regulation of angiogenesis is essential for several physiological and pathological processes, particularly for tumor development and progression. Therefore, it is important to investigate the roles served by miRs in angiogenesis as this may aid in discovering novel strategies for treating tumors via modulating angiogenesis. In this review, miRNA biogenesis, regulation and functions are described with new information and corresponding references. In particular, the latest advances in the role of various miRs and their target genes involved in tumor angiogenesis were updated. Next, different signaling pathways by which miRNAs could be regulated in different types of tumor progression were addressed. Furthermore, the potential clinical value of miRs as biomarkers for diagnosing and monitoring the response to therapy, as well as their ability to regulate tumor angiogenesis and the mechanism underlying this regulation, were investigated.
\end{abstract}

\section{Contents}

1. Introduction

2. The current research achievements in miR biogenesis

3. The role of angiogenesis in cancer

4. The functions of miRs in regulating tumor angiogenesis

5. miRs as biomarkers in patients with cancer

6. Conclusions

Correspondence to: Dr Wei Hou, Department of Oncology, Guang'anmen Hospital, China Academy of Chinese Medical Sciences, 5 Bei-Xian-Ge, Beijing 100053, P.R. China

E-mail: houwei1964@163.com

Key words: angiogenesis, microRNA, cancer, regulation, biomarker

\section{Introduction}

Cancer is a major life-threatening disease with a high incidence and mortality worldwide $(1,2)$. The mechanisms of tumor formation are complex and diverse, and the differential prognosis of cancer is associated with variations in tumor proliferation, invasion and metastasis. The basic treatment modalities for cancer are surgery, radiotherapy, chemotherapy and targeted therapy. However, it is difficult to diagnose the majority of cancers at an early stage; therefore, the curative effects of these treatments remain limited, and there is an imminent need to identify novel diagnostic and prognostic biomarkers and therapeutic targets for cancer.

Angiogenesis is the formation of new blood vessels from existing vessels. It is a pivotal process during cancer cell proliferation, migration and differentiation. Since angiogenic factors control tumor growth and metastasis (3), angiogenic regulation of this process is pivotal for identifying novel cancer treatment strategies. The latest research indicates that the dysregulated expression of microRNAs (miRs) may lead to abnormal angiogenesis (4). miRs are a class of endogenous, small and non-coding single-stranded RNA molecules containing 22 nucleotides; they regulate the expression and function of multiple genes. By binding to complementary sequences of the 3'-untranslated region of the target mRNA, miRs inhibit or degrade the post-transcriptional products of the target genes (4). Approximately 30-60\% of human genes are regulated by one or more miRs (5). In addition, a previous study reported that miRs may be considered a class of oncogenes or tumor suppressor genes (6). One study revealed that miRs in tumor cells may affect the activity of endothelial cells via non-cell-autonomous mechanisms and that miRs in endothelial cells may regulate the cell-autonomous response (7). These observations provide evidence that antiangiogenic treatment of tumors with miRs may inhibit the growth of cancer.

This review describes miR biogenesis, regulation and functions. The current research achievements in miRs biogenesis are updated here. The role of angiogenesis is pivotal in the survival of cancer cells. In this review, several critical endogenous molecules and their receptors and their expressions, which promote angiogenic activity in tumor metastasis, are expounded. Next, the functions of miRs in regulating tumor angiogenesis are described in detail. Particularly, the functions of exosomal delivery of miRs are discussed. Tight junctions exist mainly between endothelial cells. Innovatively, this review describes miRs' target on tight junction-related proteins, which is helpful to the transendothelial migration of 
tumor cells and tumor metastasis. Furthermore, the functions of miRs in hypoxic environments are described. Additionally, the latest advances in the role of various miRs and their corresponding target genes involved in tumor angiogenesis are updated. Various signaling pathways in different types of tumor progression regulated by miRs are addressed.

In summary, this review demonstrates the potential clinical value of miRs as biomarkers for diagnosing and monitoring the response to therapy, as well as their ability to regulate tumor angiogenesis and the mechanism underlying this regulation.

\section{The current research achievements in miR biogenesis}

Although miRs are only 22 nucleotides long, they serve an important role in gene expression by regulating various target genes. miRs recruit an argonaute (AGO) protein complex to a complementary target mRNA, which usually results in translation repression or mRNA degradation (8). The conventional miR biogenesis pathway consists of two cleavage events: Nuclear and cytoplasmic (9), which require approximately five post-transcriptional processing steps to yield the functional mature miRs as follows (Fig. 1): i) transcription of initial miRs (pri-miRNA), ii) formation of pre-miRs, iii) transport of pre-miRs from the nucleus to the cytoplasm, iv) production of mature miRs and $v$ ) formation of the miRNA-induced silencing complex (miRISC) core.

In the nucleus. The gene encoding miRs in the nucleus is transcribed to generate a long primary transcript among the two RNA polymerases, RNA pol II or III, which is called pri-miRNA. Pri-miRNA has methylated guanine at the $5^{\prime}$ end and a polyadenine base at the $3^{\prime}$ end. Furthermore, pri-miRNA contains sequences of uridine residues, which terminate RNA pol III transcription.

Further processing of Pri-miRNA is mainly completed in the 400-500 kDa microprocessor protein complex composed of Drosha and Pasha. Pre-miRs are catalyzed by Drosha, a nuclease of the RNase III family, while Pasha is a double-stranded RNA binding protein that participates in substrate recognition by Drosha (10). Drosha RNase III endonuclease cleaves both strands of the stem at sites near the base of the primary stem-loop, releasing 60-70 nt stem-loop intermediates, called miRNA precursors or pre-miRNA. The pre-miRNA is transported into the cytoplasm by the translocator RanGTP/Exportin-5.

MiRs residing in introns are known as mirtrons, and are widespread in Drosophila, C. elegans and vertebrates (11). The transcription of mirtrons is performed by spliceosome but not by Drosha. Next, the mirtron precursor molecule released by the spliceosome in the form of a lasso will be linearized under the action of a debranching enzyme. Subsequently, they mimic the pre-miRNA structure and directly enter the miRNA processing program and are transferred to the cytoplasm to be treated by Dicer instead of being cleaved by Drosha.

In the cytoplasm. pre-miRNA is further matured by the RNase III endonuclease Dicer in the cytoplasm (12). The loop structure is cut and modified by Dicer, and miRNA: miRNA* complexes are formed in the cytoplasm. Following helicase action, miRNA: miRNA* complexes eventually generate mature, functional single-stranded miRNAs and then combine with miRNA ribonucleoproteins, following which the miRNA* is rapidly degraded.

Typically, one strand of this mature miRNA duplex, termed the guide strand, can enter the RNA-induced silencing complex (RISC), and the other strand is removed. The miRISC complex contains Dicer, TRBP, PACT and Gemin3; however, the AGO factor directly binds to the miRNA and can mediate the sequence matching of the miRNA and the target mRNA to cause subsequent translational inhibition.

\section{The role of angiogenesis in cancer}

Malignant tumors invade neighboring tissues and metastasize through the bloodstream to distant organs. Therefore, expanding the blood vasculature is pivotal in the survival of cancer cells. Vascular endothelial growth factor (VEGF), a specific mitogen of vascular endothelial cells, is overexpressed in numerous malignant tumors (13). VEGF may bind to its receptors (VEGFRs) expressed on the vascular endothelial cells and promote endothelial cell division, migration and proliferation, and induce capillary angiogenesis and growth into tumor tissue $(14,15)$. Platelet-derived growth factor (PDGF) mainly originates from mesenchymal cells and participates in the induction of angiogenesis (16). The main functions of PDGF and its receptor, PDGFR, involve autocrine stimulation of tumor cells, paracrine stimulation of tumor stromal cells to promote angiogenesis, and regulation of the interstitial fluid pressure to control the flow of drugs into and out of the tumor (16).

CD31 is overexpressed on the surface of vascular endothelial cells. Its distribution is associated with angiogenesis, as well as the movement of endothelial cells (17). CD31 acts as a bridge between tumor and vascular endothelial cells to promote the metastasis of malignant tumor cells (18). Therefore, CD31 is a useful marker for evaluating tumor angiogenesis (18).

Endogenous molecules that promote angiogenic activity serve several major roles in promoting tumor metastasis. These include stimulating the growth and survival of endothelial cells to ensure angiogenesis (19), breaking the tight junctions of tumor vascular endothelial cells and promoting tumor metastasis $(15,20)$ to ensure that the new tumor cells can obtain oxygen and nutrition to grow rapidly and provide favorable conditions to transport cancer cells for distant metastases $(21,22)$.

\section{The functions of miRs in regulating tumor angiogenesis}

Several studies have demonstrated that miRs may affect cell proliferation, differentiation, metabolism and tumor angiogenesis $(6,14)$. A single miR can target several mRNAs. In addition, aberrant miR expression can disrupt the expression of several mRNAs and proteins involved in regulating cell proliferation and apoptosis. Diverse miRs are involved in tumor angiogenesis, affecting both anti- and pro-angiogenic proteins (6). Here, the functions of miRs in regulating tumor angiogenesis in the following sections are reviewed.

Exosomal miRs and tumor angiogenesis. Exosomes, the nanovesicles with diameters ranging between 30 and $150 \mathrm{~nm}$, 


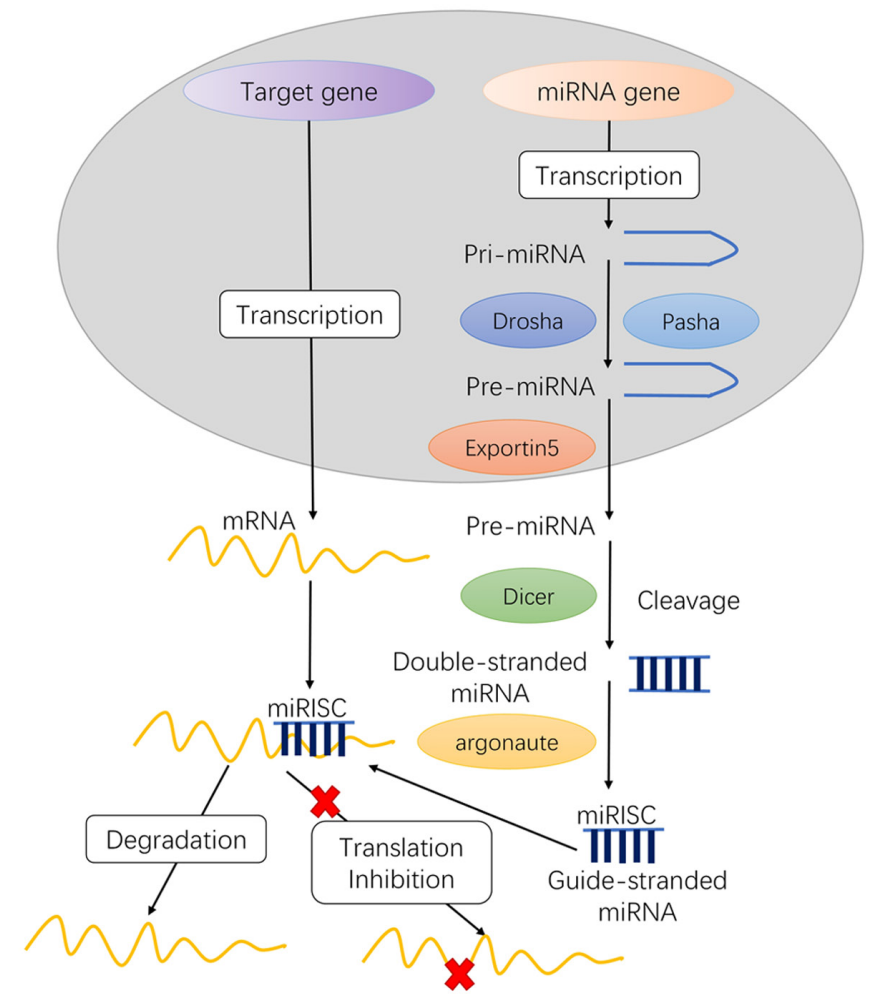

Figure 1. miR biogenesis in animals. i) pri-miRNA transcription; ii) formation of pre-miRs; iii) pre-miRNA transportation into the cytoplasm; iv) pre-miRNA maturation in the cytoplasm; and v) miRISC core formation. miR/miRNA, microRNA; miRISC, miRNA-induced silencing complex.

are involved in cell-to-cell communication and regulate various biological processes (23). In the tumor microenvironment, exosomes released by different types of cells regulate tumor survival, growth and facilitate tumor cell dissemination (24). Although miRs are one of the key regulators of gene expression, exosomal miRs serve a dual role in cancer. Exosomal delivery of miRs to recipient cancer or stromal cells may induce cancer progression and metastasis (25). However, exosomes also facilitate tumor initiation by affecting signaling pathways and inhibiting the expression of tumor suppressors (25). A previous study demonstrated that miRs are packaged and secreted by exosomes and are potential biomarkers as well as important mediators of interactions among different cells (23). Notably, exosomal miRs are implicated in modulating endothelial cell functions and angiogenesis in cancer $(26,27)$.

High levels of miR-205 were observed in ovarian cancer (OC) tissue and adjacent endothelial cells and were associated with metastatic progression in patients with OC (28). In addition, miR-205 was markedly enriched in the serum and circulating exosomes of patients with OC (28). miR-205 in exosomes secreted by OC cells significantly promoted angiogenesis in vitro and accelerated angiogenesis and tumor growth in vivo via the phosphatase and tensin homolog (PTEN)-Akt pathway (28). miR-141-3p present in small extracellular vesicles (sEV) secreted by epithelial OC cells is an important mediator of intercellular communication (29). Furthermore, it can regulate the expression of VEGFR-2 and reactive oxygen species-dependent activation of nuclear factor $\kappa-\mathrm{B}(\mathrm{NF}-\kappa \mathrm{B})$ signaling in endothelial cells and promote endothelial cell angiogenesis (29). Another study based on in vitro and in vivo experiments reported that $\mathrm{miR}-204-5 \mathrm{p}$ promoted angiogenesis in OC via thrombospondin 1 (30).

The serum level of exosomal miR-21 is increased in patients with hepatocellular carcinoma (HCC) making it a potential biomarker for HCC (31). This aforementioned study demonstrated that miR-21 derived from HCC cells activated pyruvate dehydrogenase kinase 1/Akt signaling in hepatic stellate cells. Cancer progression was promoted by increased secretion of angiogenic cytokines, including VEGF, matrix metalloproteinase (MMP)2, MMP9, basic fibroblast growth factor and transforming growth factor (TGF)- $\beta$. Furthermore, decreased miR-451a content was observed in serum-derived exosomes isolated from patients with HCC. miR-451a suppressed human umbilical vein endothelial cell (HUVEC) migration, tube formation and vascular permeability. As the critical target of miR-451a, LPIN1 promoted apoptosis in HCC cell lines and HUVECs (32).

A previous study that comprehensively analyzed miR-9 expression demonstrated that it was overexpressed in glioma specimens and cells and contributed toward their enhanced proliferation, migration and invasion (33). Additionally, collagen alpha-1 (XVIII), thrombospondin 2 (THBS-2), protein patched homolog 1 (PTCH1) and prolyl hydroxylase 3 (PHD3) were verified as direct targets of miR-9 (33). miR-9 in glioma cell exosomes was absorbed by vascular endothelial cells, thereby inducing angiogenesis (33). Glioma stem cells also contained exosomes overexpressing miR-26a, which significantly increased proliferation and angiogenesis by inhibiting PTEN (34).

Exosome-delivered miR-135b contribute significantly toward angiogenesis in gastric cancer (GC). GC cells secrete exosomal miR-135b that directly targets forkhead box $\mathrm{O} 1$ (FOXO1), suppresses the expression of the FOXO1 protein, and enhances the growth of blood vessels (35). Another study revealed that miR-142-3p in EVs secreted by lung adenocarcinoma cells affected endothelial and fibroblast cells and promoted angiogenesis via inhibiting TGF $\beta$ receptor 1 (36). This demonstrates a role for EVs in cell-cell communication. The level of miR-501-3p is highly enriched in pancreatic ductal adenocarcinoma (PDAC) tissues and tumor-associated macrophage-derived exosomes. Treatment of M2 macrophages with miR-501-3p activated the TGF- $\beta$ signaling pathway and downregulated TGF- $\beta$ receptor 3 expression in PDAC cells. Furthermore, suppression of miR-221-3p in exosomes secreted by macrophages inhibited tumor formation and metastasis in vivo (37).

In colorectal carcinoma (CRC), colon cell-derived EVs contain large amounts of miR-92a-3p and have a pro-angiogenic function. Genes encoding Dickkopf-3 and claudin-11 were identified as targets of miR-92a-3p. In endothelial cells, the ectopic expression of miR-92a-3p upregulated the expression of genes associated with the cell cycle and mitosis while downregulating the expression of genes associated with adhesion (38). The study also demonstrated that exosomal miR-1229 was highly enriched in the serum of patients with CRC and was associated with tumor size, lymphatic metastasis, TNM stage and poor survival. Notably, anti-miR-1229 therapy inhibited tumor growth and angiogenesis in vivo. In addition, HIPK2 was identified as a target of circulating exosomal miR-1229 and influenced the angiogenesis of HUVECs via the VEGF pathway (39). 


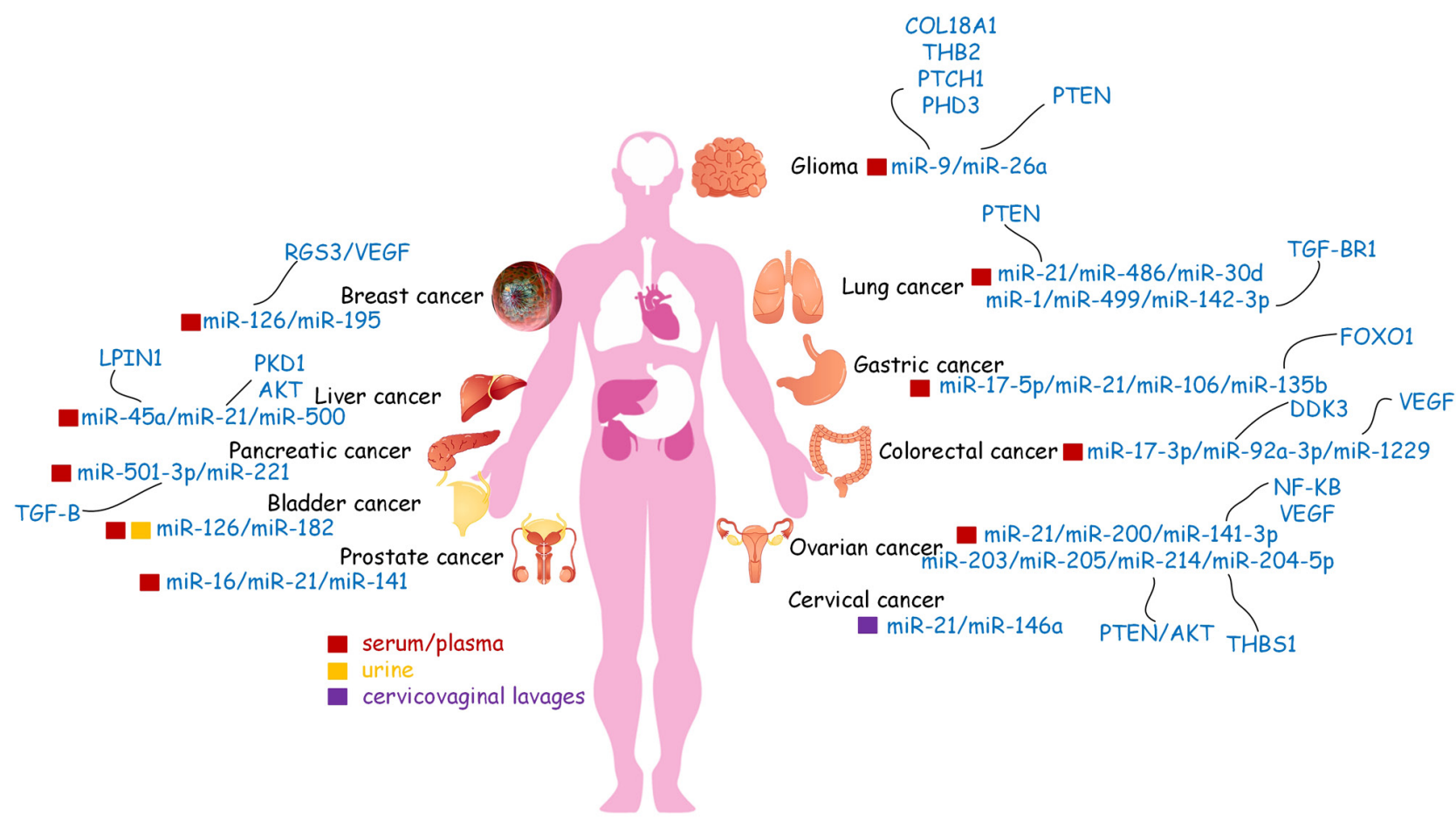

Figure 2. Circulating microRNAs (miRs) may serve as biomarkers in human body fluids for various types of cancer. Liquid biopsy is a less invasive method that may detect cancer biomarkers more frequently and efficiently than other methods and is a good candidate method for future use in cancer diagnosis. miRs, microRNAs; VEGF, vascular endothelial growth factor; VEGFR, VEGF receptor; RGS3, regulator of G protein signaling 3; PKD1, polycystin 1; LPIN1, lipin 1; TGF- $\beta$, transforming growth factor- $\beta$; TGF- $\beta$ R 1, TGF- $\beta$ receptor 1 ; COL18A1, collagen type XVIII alpha 1 chain; THB2, truncated hemoglobin 2 ; THBS1, thrombospondin 1; PTCH1, patched 1; PHD3, prolyl hydroxylase 3; PTEN, phosphatase and tensin homolog; FOXO1, forkhead box O1; NF-kB, nuclear factor $\kappa-B$.

Functions of miRs in regulating tumor metastasis caused by tight junctions. Tight junctions exist mainly between endothelial cells or between epithelial and endothelial cells. These junctions make membranes of adjacent cells tightly connected and serve a role in the paracellular permeability barrier and maintenance of cell polarity $(40,41)$. Disruption of tight junctions enhances the permeability of vascular endothelial cells and promotes the transendothelial migration of tumor cells, thereby forming a protumor niche and promoting tumor metastasis (27).

Tight junctions are composed of a variety of proteins. Previous studies have demonstrated that the abnormal expression of claudin, occludin and zona occluden (ZO) is associated with the proliferation, invasion and metastasis of tumor cells $(42,43)$. Claudin serves an important barrier protective role to maintain the selective permeability of vascular endothelial cells. The occludin protein generates a paracellular block by binding to adjacent cells via the outer part of the cell membrane (44). Zonula occludens-1 (ZO-1) is a central regulator of intercellular junctions in endothelial cells; it regulates junctional tension and linkage of vascular endothelial-cadherin junctions (45). Other proteins, including ZO-1/2/3, cingulin and multi-PDZ domain protein 1 , are skeleton proteins that connect transmembrane proteins to the actin cytoskeleton. ZO-1 can interact with a variety of tight junction proteins, regulate intracellular and extracellular signal transduction pathways, affect the function of tight cell junctions and regulate cell permeability $(27,45)$.

Different miRs exert different regulatory effects on tight junction-related proteins (Fig. 2), thereby promoting tumor metastasis. By targeting krüppel-like Factor 2 (KLF2/4), cancer-derived exosomal miR-25-3p was transferred to vascular endothelial cells. miR-25-3p regulated the expression of VEGFR2, ZO-1, occludin and claudin 5 in endotheliocytes, and promoted pre-metastatic niche formation by inducing vascular permeability and angiogenesis (27). Another study revealed that overexpression of miR-25-3p enhanced the migration and invasion ability of non-small cell lung cancer (NSCLC) cells (46). As one of the diagnostic markers in lung cancer, the expression of miR-25 is associated with lymph node metastasis, pathological stage and overall survival $(47,48)$. Angiogenesis, vascular permeability and cancer transendothelial migration were enhanced by exosomal miR-23a by targeting $P H D$ and $Z O-1$ in lung cancer (26). Furthermore, miR-105 secreted by metastatic breast cancer cells destroyed vascular endothelial barriers to promote metastasis by targeting ZO-1 (49). Furthermore, the expression of miR-21 increased significantly in a tight junction barrier defect model; therefore, miR-21 may regulate intestinal epithelial tight junction permeability via the PTEN/phosphoinositide 3-kinase (PI3K)/Akt signaling pathway (50).

Angiogenesis in a hypoxic environment. Hypoxia-inducible factor (HIF) is a transcription factor that serves a key role in the cellular response to hypoxia. HIF is closely involved in tumorigenesis by regulating cell survival, angiogenesis, metastasis, adaptation to the hypoxic tumor microenvironment, and suppression of host immunity to drive cancer progression (51). Hypoxia is a pivotal factor required for activating angiogenesis 
as it induces the expression and release of pro-angiogenic molecules, including VEGF, PDGF and CD31, from the stroma and tumor cells (52).

Hypoxia-induced exosomes may influence macrophage recruitment and promote M2-like polarization. By transferring let-7a miR, hypoxic tumor exosomes enhanced oxidative phosphorylation in bone marrow-derived macrophages and suppressed the insulin-Akt-mammalian target of rapamycin (mTOR) signaling pathway (53). Therefore, hypoxia promotes secretion of exosomes from tumors that may modify the immunological effects of infiltrating monocytes-macrophages, thereby helping tumor to escape host immunity and grow (53).

miR-23a is significantly upregulated in exosomes secreted by lung cancer under hypoxic conditions (26). Exosomal miR-23a directly inhibited its target genes, PHD1 and $P H D 2$, leading to the accumulation of HIF-1 $\alpha$ in endothelial cells, thereby enhancing angiogenesis in hypoxic lung cancer cells. Furthermore, miR-21-5p derived from hypoxia pre-challenged mesenchymal stem cell-derived extracellular vesicles (MSC-EVs) promoted A549 cell growth and mobility as well as macrophage M2 polarization. Knockdown of miR-21-5p significantly inhibited lung cancer progression and macrophage M2 polarization. Hypoxic MSC-EVs significantly enhanced tumor growth, cancer cell proliferation, intra-tumoral angiogenesis and macrophage M2 polarization, while downregulating PTEN, programmed cell death protein 4 (PDCD4) and reversion-inducing cysteine-rich protein with kazal motifs (RECK) gene expression via miR-21-5p. By contrast, overexpression of PTEN, PDCD4 and RECK in A549 cells significantly mitigated the antiapoptotic and pro-metastatic effects of hypoxic MSC-EVs (54). Furthermore, miR-765, which targets several protein-encoding genes involved in angiogenesis and vasculogenic mimicry, is downregulated by hypoxia. The upregulation of miR-574-5p enhanced angiogenesis, suppressed the expression of tyrosine protein phosphatase non-receptor type 3 , and enhanced phosphorylation of $\mathrm{p} 44 / 42$ mitogen-activated protein kinases in GC cells in hypoxic environments (55). As a hypoxia-specific miR overexpressed in GC, miR-210 regulated HIF-1 $\alpha$ expression, facilitated the epithelial-mesenchymal transition (EMT) and angiogenesis in response to hypoxia during tumorigenesis, and inhibited chemoresistance, invasion and metastasis by targeting homeobox protein Hox-A9 (Hoxa9) (56). Binding to hypoxia response elements promoted metabolic switching to aerobic glycolysis (57). Low expression of miR-186 promoted aerobic glycolysis, suppressed cell proliferation by downregulating HIF-1 $\alpha$, and consequently affected programmed death ligand 1, hexokinase 2 and platelet-type phosphofructokinase in GC (58).

Functions of miRs in regulating major tumor angiogenesis pathways. A single miR may target multiple transcripts in different types of cells, or an individual transcript may be regulated by multiple miRs (59). Angiogenesis serves a pivotal role in tumor growth, progression and metastasis, which are complex processes involving essential signaling pathways (60). miRs participate in multiple aspects regulating vascular development and the angiogenic response (61). Essential signaling pathways, including VEGF and Notch, may affect the angiogenic switch and carcinogenesis (62). VEGFA is directly targeted by a diverse range of miRs in various types of cancer. For example, miR-150-5p inhibits CRC cell proliferation, migration, invasion and angiogenesis in vitro and in vivo by inactivating the VEGFA/VEGFR2 signaling pathway (63). In summarize, all the known tumor angiogenesis pathways regulated by miRs are basically in either of two ways: i) promoting angiogenesis by targeting the negative regulators of angiogenesis or ii) inhibiting vascularization by targeting positive regulators. miR-29c, miR-942, miR-21, miR-526b, miR-655, miR-632, miR-130b, miR-103a-3p, miR-382-5p and miR-26a are reported to be pro-angiomiRs. They target various inhibitory signaling pathway, including VEGF signaling pathway, PDCD4/c Jun signaling pathway, NF- $\kappa \mathrm{B}$ signaling pathways or PI3K/Akt pathway-related molecules of angiogenesis and promote tube formation. miR-181d-5p, miR-195, miR-126, miR-4306, miR-199b-5p, miR-1249, MiR-150-5p/miR-193a-3p, miR-622, miR-7, miR-204, miR-195-5p, miR-765, miR 335 , miR-885-5p and miR-136 are termed anti-angiomiRs, which inhibit capillary formation and angiogenesis via the VGFA/VEGFR2 pathway, ERK signaling pathways, ALK1/Smad/Id1 pathway, GSK3 $\beta / \beta$-catenin and Akt/mTOR pathway. In the following sections, the angiogenesis pathways in different types of cancer will be discussed and the findings are summarized in Table I.

Lung cancer. Angiogenesis serves an important role in the progression of NSCLC. Plasmacytoma variant translocation 1 (PVT1) is overexpressed in NSCLC and its upregulation is associated with angiogenesis in NSCLC. One study demonstrated that PVT1 promoted angiogenesis by targeting the miR-29c/VEGF signaling pathway in NSCLC (64). Another study reported that miR-942 promoted NSCLC cell migration, invasion, EMT-related metastasis and angiogenesis by directly targeting BARX homeobox 2 (BARX2) in vitro and in vivo (65). Furthermore, the expression of cyclin-dependent kinase inhibitor 3 (CDKN3) was increased, while miR-181d-5p was depleted in NSCLC, which suppressed NSCLC cell proliferation, invasion, migration, angiogenesis and the EMT, and increased apoptosis via the Akt signaling pathway inactivation (66). It provided a clear understanding of the mechanisms of the miR-181d-5p/CDKN3/Akt axis in NSCLC progression and may serve as a prognostic marker for of NSCLC treatments in the future. Another study demonstrated that miR-21 directly targeted PTEN and increase proliferation, migration and tube formation in HUVEC cells (67). Increasing miR-21 induced the accumulation of VEGF and HIF-1 $\alpha$ in cells via the PI3K/Akt signaling pathway (67). miR-21 may be potentially involved in pathophysiology. In squamous cell lung cancer (SQCLC), miR-195 acts as a tumor suppressor, inhibiting the viability, growth and migration of SQCLC cells by targeting VEGF and inhibiting angiogenesis in tumors (68). Additionally, miR-195 promotes apoptosis and inhibits proliferation in various types of cancer. In summary, the results may provide novel insights for developing prognostic markers and efficacious strategies for clinical therapy of NSCLC and SQCLC.

Breast cancer. The roles of angiogenesis in breast cancer tumour growth and metastasis are well established. Breast cancer metastasis requires the access of tumor cells into the blood vessels. A previous study demonstrated that miR-126-3p 
Table I. Angiogenesis pathways in different types of cancer.

\begin{tabular}{|c|c|c|c|c|c|}
\hline Non-coding RNAs & Target & $\begin{array}{l}\text { Up-/down- } \\
\text { regulation }\end{array}$ & Functions & Cancer type & (Refs.) \\
\hline $\operatorname{miR}-29 c$ & PVT1 & Upregulation & $\begin{array}{l}\text { Promoted angiogenesis } \\
\text { VEGF pathway }\end{array}$ & NSCLC & $(64)$ \\
\hline miR-942 & BARX2 & Upregulation & $\begin{array}{l}\text { Promoted cell migration, invasion, } \\
\text { metastasis and EMT }\end{array}$ & NSCLC & $(65)$ \\
\hline $\operatorname{miR}-181 d-5 p$ & CDKN3 & Downregulation & $\begin{array}{l}\text { Suppressed proliferation, invasion, } \\
\text { migration, angiogenesis and } \\
\text { EMT, and increased cell apoptosis }\end{array}$ & NSCLC & $(66)$ \\
\hline $\operatorname{miR}-21$ & PTEN & Upregulation & PI3K/Akt signaling pathway & NSCLC & $(67)$ \\
\hline miR-195 & VEGF & Downregulation & $\begin{array}{l}\text { Suppressed the viability and } \\
\text { migration and angiogenesis }\end{array}$ & SQCLC & $(68)$ \\
\hline $\operatorname{miR}-126$ & RGS3/VEGF & Downregulation & $\begin{array}{l}\text { Inhibited the proliferation, } \\
\text { migration, invasion and } \\
\text { angiogenesis }\end{array}$ & Breast cancer & $(69,70)$ \\
\hline $\operatorname{miR}-4306$ & $\begin{array}{l}\text { SIX1/Cdc42/ } \\
\text { VEGFA }\end{array}$ & Downregulation & $\begin{array}{l}\text { Suppressed TNBC cell } \\
\text { proliferation, migration and } \\
\text { invasion and abrogates } \\
\text { angiogenesis }\end{array}$ & Breast cancer & (71) \\
\hline $\begin{array}{l}\operatorname{miR}-526 b \\
\text { and miR-655 }\end{array}$ & PTEN & Upregulation & $\begin{array}{l}\text { Upregulated the angiogenesis and } \\
\text { lymphangiogenesis markers, } \\
\text { inhibited HIF-1 } \alpha \text { and the PI3K/Akt } \\
\text { pathway }\end{array}$ & Breast cancer & $(72)$ \\
\hline $\operatorname{miR}-199 b-5 p$ & ALK1 & Downregulation & $\begin{array}{l}\text { Attenuated ALK1/Smad/Id1 } \\
\text { pathway }\end{array}$ & Breast cancer & (73) \\
\hline $\operatorname{miR}-1249$ & $\begin{array}{l}\text { VEGF } \\
\text { A/HMGA2 }\end{array}$ & Downregulation & $\begin{array}{l}\text { Suppressed colorectal cancer } \\
\text { cell proliferation, migration, } \\
\text { invasion, and angiogenesis, } \\
\text { regulate Akt/mTOR pathway and } \\
\text { EMT }\end{array}$ & Colorectal cancer & (74) \\
\hline miR-150-5p/miR-193a-3p & VEGFA & Downregulation & $\begin{array}{l}\text { Inhibited cell proliferation, } \\
\text { migration, invasion and } \\
\text { angiogenesis, VEGFA/VEGFR2 } \\
\text { and Akt/mTOR signaling pathway }\end{array}$ & Colorectal cancer & $(63,75)$ \\
\hline $\operatorname{miR}-622$ & VEGFA & Downregulation & $\begin{array}{l}\text { Suppressed the CXCR4-VEGFA } \\
\text { signaling axis }\end{array}$ & Colorectal cancer & (76) \\
\hline miR-7 & EGFR & Downregulation & ERK signaling pathway & Colorectal cancer & $(77)$ \\
\hline miR-204 & BIRC2 & Downregulation & $\begin{array}{l}\text { Suppressed NF- } \kappa \text { B signaling } \\
\text { pathways }\end{array}$ & Gastric cancer & $(78)$ \\
\hline miR-632 & TFF1 & Upregulation & $\begin{array}{l}\text { Improved tube formation and } \\
\text { endothelialcell recruitment, } \\
\text { accelerating angiogenesis }\end{array}$ & Gastric cancer & (79) \\
\hline miR-195-5p & PSAT1 & Downregulation & $\begin{array}{l}\text { Inhibited GSK } 3 \beta / \beta \text {-catenin } \\
\text { signaling pathway }\end{array}$ & Ovarian cancer & $(80)$ \\
\hline miR-765 & VEGFA & Downregulation & $\begin{array}{l}\text { Decreased the VEGFA/ } \\
\text { Akt1/SRC- } \alpha \text { axis }\end{array}$ & Ovarian cancer & $(82)$ \\
\hline $\operatorname{miR}-130 b$ & TNF- $\alpha$ & Upregulation & $\begin{array}{l}\text { Attenuated NF- } \kappa \text { B signaling } \\
\text { and its downstream gene VEGFA }\end{array}$ & Prostate cancer & $(83)$ \\
\hline $\operatorname{miR}-335$ & EGR3 & Downregulation & $\begin{array}{l}\text { Reduced the activity of } \\
\text { caspase- } 3 \text { and } \\
\text { inflammatory factor }\end{array}$ & Prostate cancer & $(84)$ \\
\hline miR-103a-3p and miR-382-5p & $\mathrm{ZIC4}$ & Upregulation & $\begin{array}{l}\text { Activated PI3K/Akt signaling } \\
\text { pathway }\end{array}$ & Glioma & $(85)$ \\
\hline
\end{tabular}


Table I. Continued.

\begin{tabular}{|c|c|c|c|c|c|}
\hline Non-coding RNAs & Target & $\begin{array}{l}\text { Up-/down- } \\
\text { regulation }\end{array}$ & Functions & Cancer type & (Refs.) \\
\hline $\operatorname{miR}-26 a$ & PTEN & Upregulation & Activated the PI3K/Akt signaling pathway & Glioma & $(34)$ \\
\hline miR-885-5p & AEG-1 & Downregulation & $\begin{array}{l}\text { Inhibited cell migration, invasion, proliferation, } \\
\text { angiogenesis and EMT }\end{array}$ & $\begin{array}{l}\text { Hepatocellular } \\
\text { carcinoma }\end{array}$ & $(86)$ \\
\hline $\operatorname{miR}-30 e-5 p$ & AEG-1 & Downregulation & Implicated in the angiogenesis and metastasis & $\begin{array}{l}\text { Squamous } \\
\text { cell cancer of } \\
\text { the head and } \\
\text { neck }\end{array}$ & $(87)$ \\
\hline $\operatorname{miR}-136$ & MAP2K4 & Downregulation & $\begin{array}{l}\text { Inhibited angiogenesis and cell } \\
\text { proliferation, and promoted apoptosis }\end{array}$ & $\begin{array}{l}\text { Gallbladder } \\
\text { cancer }\end{array}$ & $(88)$ \\
\hline $\operatorname{miR}-21$ & PDCD4 & Upregulation & Regulated PDCD4/c-Jun signaling pathway & $\begin{array}{l}\text { Renal cell } \\
\text { carcinoma }\end{array}$ & $(89)$ \\
\hline
\end{tabular}

miR, microRNA; NSCLC, non-small cell lung cancer; SQCLC, squamous cell lung cancer; EMT, epithelial-mesenchymal transition; PI3K, phosphoinositide 3-kinase; TNBC, triple-negative breast cancer; HIF, hypoxia-inducible factor; Id1, inhibitor of differentiation 1; mTOR, mammalian target of rapamycin; CXCR4, C-X-C motif chemokine receptor 4; ERK, extracellular signal-regulated kinase; GSK3 $\beta$, glycogen syntheses kinase 3 $\beta$; BARX2, BARX homeobox 2; CDKN3, cyclin dependent kinase inhibitor 3; PTEN, phosphatase and tensin homolog; VEGF, vascular endothelial growth factor; VEGFR2, VEGF receptor2; RGS3, regulator of G protein signaling 3; SIX1, SIX homeobox 1; Cdc42, cell division cycle 42; ALK1, activin receptor-like kinase-1; HMGA2, high mobility group AT-hook 2; EGFR, epidermal growth factor receptor; BIRC2, baculoviral IAP repeat containing 2; TFF1, trefoil factor 1; PSAT1, phosphoserine aminotransferase 1; TNF- $\alpha$, tumor necrosis factor- $\alpha$; EGR3, early growth response 3; ZIC4, Zic family member 4; AEG-1, astrocyte elevated gene-1; MAP2K4, mitogen-activated protein kinase kinase 4; PDCD4, programmed cell death 4.

expression is downregulated in triple-negative breast cancer (TNBC) cells (69). Regulator of G-protein signaling 3 ( $R G S 3$ ) is a direct target of miR-126-3p in TNBC. Overexpression of miR-126-3p inhibited the proliferation, migration, invasion and angiogenesis of TNBC. Another study reported that miR-126 regulated VEGF and was overexpressed in MCF7 cells, which was associated with a decrease in cell proliferation (70). miR-126 may be regarded as a promising therapy to increase breast cancer survival. Furthermore, the upregulation of miR-4306 significantly suppressed TNBC cell proliferation, migration and invasion, and abrogated angiogenesis and lymphangiogenesis in vitro and in vivo (71). Mechanistic analyses indicated that miR-4306 inactivated the signaling pathways mediated by its direct targets, SIX1/Cdc42/VEGFA. Estrogen is of paramount importance in breast cancer. However, there is no preferred standard form of chemotherapy for TNBC. The study verified that miR-4306 could promote cisplatin-induced apoptosis, suggesting that a miR-4306 mimic combined with cisplatin treatment in TNBC may represent a promising targeted therapy with high specificity and limited toxicity (71). Notably, studies on breast cancer have reported that the overexpression of miR-526b and miR-655 upregulates the angiogenesis and lymphangiogenesis markers, including VEGFA, VEGFC, VEGFD, CD31 and LYVE1 (72); mechanistic research confirmed that PTEN was a target of both miRs. PTEN inhibited HIF-1 $\alpha$ and the PI3K/Akt pathway, and dysregulation of these pathways via PTEN resulted in VEGF-overexpression. Additionally, miR-199b-5p-overexpression inhibited the mRNA and protein expression of activin receptor-like kinase 1 , and the formation of capillary-like tubular structures in HUVECs. Furthermore, it attenuated the induction of the activin receptor-like kinase 1/Smad/Id1 pathway in HUVECs (73). These findings further establish the involvement of these miRNAs in breast cancer metastasis and their potential as future breast cancer biomarkers.

Colorectal cancer. VEGFA is directly targeted by miR-1249 and suppresses CRC cell proliferation, migration, invasion and angiogenesis (74). The study verified that miR-1249 was a potentially effective target for treating CRC, via the Akt/mTOR pathway and that the EMT process of CRC cells was inhibited by targeting VEGFA and high-mobility group AT-hook 2. Furthermore, a study reported that the gene encoding VEGFA was directly targeted by miR-150-5p in CRC (63). miR-150-5p (63) and miR-193a-3p (75) inhibited cell proliferation, migration, invasion and angiogenesis, and inactivated the VEGFA/VEGFR2 and Akt/mTOR signaling pathways (63). In addition, miR-622-overexpression inhibited CRC microvessel density and angiogenesis in vitro and in vivo, by suppressing the CXCR4-VEGFA signaling axis (76). Another study reported that the gene encoding EGFR was a target of miR-7 (77). In CRC tissues, the expression of EGFR and microvascular density are increased, while miR-7 expression is decreased. With the overexpression of miR-7 and silencing of EGFR, vasculogenic mimicry and density, cell migration, and cell invasion were suppressed via the extracellular signal-regulated kinase signaling pathway. Anti-angiogenesis therapy is an important strategy of cancer treatment, the research not only provides a novel insight into the mechanism of CRC progression but also highlights miR-1249, miR-150-5p, miR-193a-3p, miR-622 and miR-7 as potential biomarkers and therapeutic targets for CRC. 


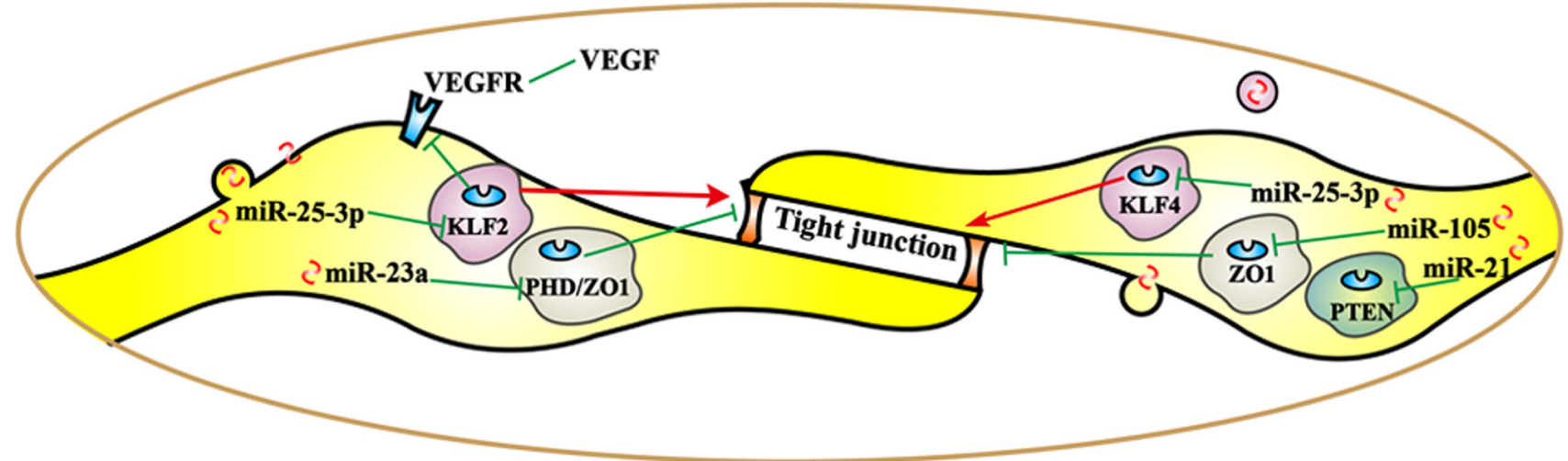

Figure 3. Regulation of miRs secreted by cancer cells in tight junctions and niche formation of a pre-metastatic microenvironment. miRs, microRNAs; VEGF, vascular endothelial growth factor; VEGFR, VEGF receptor; PHD, prolyl hydroxylase; KLF, krüppel-like family; PTEN, phosphatase and tensin homolog; ZO1, zonula occludens 1 .

Gastric cancer. A previous study reported that baculoviral IAP repeat-containing 2 (BIRC2) was a target gene for miR-204 and that overexpressing miR-204 inhibited GC cell growth and metastasis; furthermore, miR-204-overexpression suppressed the tumor necrosis factor (TNF)- $\alpha$-induced activation of the NF- $\kappa B$ signaling pathways, which decreased tube formation in HUVECs, leading to GC progression (78). Another study reported that miR-632, which targets the gene encoding trefoil factor 1 (TFF1), was overexpressed in GC tissue and serum. miRs may regulate $T F F 1$ expression and secretion. Recombinant $T F F 1$ reversed miR-632-mediated angiogenesis, and downregulated $T F F 1$-induced tube formation and endothelial cell recruitment (79). As important regulators of gene expression, miRs have not only been implicated in various signaling pathways but also in anticancer therapy, and other biological processes. They provide predictive information for patients with early GC and have the potential to be applied in endoscopic treatment.

$O C$. OC is one of the leading causes of cancer-related mortalities among females. miRs have been proven to be vital to the development and progression of OC, particularly in affecting chemotherapy resistance and vasculogenic mimicry formation. miR-195-5p directly targets phosphoserine aminotransferase 1 (PSAT1) and its expression is downregulated in OC tissues (80). The GSK3 $\beta$ signaling pathway is correlated with enhanced cell apoptosis and decreased DDP-resistance to OC (81). Overexpression of miR-195-5p or silencing PSAT1 decreased glycogen synthase kinase $3 \beta$ (GSK3 $\beta$ ) phosphorylation, decreased the expression of HIF-1 $\alpha$, VEGF and $\beta$-catenin, and promoted apoptosis in OC (80). Inhibition of the GSK3 $\beta / \beta$-catenin signaling pathway was involved in the angiogenesis regulation process. The study revealed that miR-195-5p inhibited angiogenesis, decreased chemotherapy resistance of $\mathrm{OC}$ to DDP, and promoted OC cell apoptosis, demonstrating that miR-195-5p may serve as a therapeutic target for OC treatment. In addition, miR-765 decreased the levels of VEGFA, Akt1 and SRC- $\alpha$ in SKOV3 OC cells, and negatively regulated VEGFA by specific binding to its 3'-untranslated region. The miR-765 expression and VEGFA, Akt1 and SRC- $\alpha$ levels were associated with the patient outcome. Furthermore, miR-765 suppressed the formation of 3D channels-like structures through modulation of negatively regulated VEGFA and downregulated the VEGFA/Akt1/SRC- $\alpha$ axis in OC (82). miR-765 is a relevant type of hypoxia-regulated $\mathrm{miR}$ and is involved in angiogenesis and the early stages of vasculogenic mimicry formation.

Prostate cancer. Expression of miR-130b is significantly downregulated in prostate cancer cell lines. Downregulation of miR-130b significantly promoted the proliferation, invasion and tubule formation in HUVECs, and regulated TNF- $\alpha$ directly. miR-130b attenuated NF- $\mathrm{NB}$ signaling and its downstream gene, VEGFA, by directly inhibiting TNF- $\alpha$ expression. VEGFA, in turn, decreased the expression of miR-130b, thereby forming a negative feedback loop to induce angiogen-

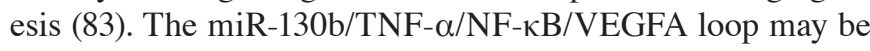
an effective therapeutic target for future prostate cancer treatment. Additionally, miR-335-overexpression decreased the expression of inflammatory factors, and significantly inhibited the viability and formation of regenerative tubes by prostate cancer cells. Silencing the early growth response protein 3 (EGR3), a possible target of miR-335, suppressed the proliferation and angiogenesis of DU145 cells, decreased the activity of caspase-3, and downregulated interleukin (IL)-6, IL-8 and IL-1 $\beta$ inflammatory factor expression (84). miR-335 may function as a potential tumor suppressor of prostate cancer and may act as a potential biomarker in treating patients with prostate cancer.

Glioma. In glioma, circ-DICER1 regulates the expression of miR-103a-3p and miR-382-5p in glioma-exposed endothelial cells. The MOV10, circ-DICER1, ZIC4 and Hsp90 $\beta$ proteins are upregulated in glioma. Hsp90 promotes the viability, migration and tube formation of glioma-exposed endothelial cells by activating the PI3K/Akt signaling pathway (85). The study provided novel mechanisms (MOV10/circ-DICER1/miR-103a-3p/miR-382-5p/ZIC4 pathway) and their vital roles in angiogenesis regulation in anti-angiogenesis therapies for glioma. Glioma stem cells (GSCs) are involved in cancer initiation and metastasis, potentially releasing exosomes that mediate cellular communication 
Table II. miR biomarkers for different types of cancer in body fluids.

\begin{tabular}{llll}
\hline Type of cancer & \multicolumn{1}{c}{ miR } & \multicolumn{1}{c}{ Source } \\
\hline Ovarian & miR-21, miR-141, miR-200, miR-203, miR-205, miR-214 & \multicolumn{1}{c}{ Serum/Plasma/Exosomes } \\
Breast & miR-195 & Serum/Plasma & $(98,99)$ \\
Prostate & miR-16, miR-21, miR-141 & Serum/Plasma & $(100)$ \\
Gastric & miR-17-5p, miR-21, miR-106 & Serum/Plasma & $(101)$ \\
Glioma & miR-21 & Serum/Plasma & $(102)$ \\
Lung & miR-21, miR-486, miR-30d, miR-1, miR-499 & Serum/Plasma & $(103)$ \\
Liver & miR-500 & Serum/Plasma & $(106)$ \\
Bladder & miR-126, miR-182 & Serum/Plasma/urine/Exosomes \\
Esophageal & miR-21 & Serum/Plasma & $(107,108)$ \\
Cervical & miR-21, miR-146a & cervicovaginal lavages/Exosomes \\
Oral & miR-125, miR-200a & Saliva & $(110)$ \\
Colorectal & miR-17-3p, miR-92 & Serum/Plasma & $(111)$ \\
\hline
\end{tabular}

miR, microRNA.

by delivering miRs. Furthermore, GSCs-derived exosomes regulate angiogenesis by modulating microvessel endothelial cells. GSCs-derived exosomes contain high levels of miR-26a, which activates the PI3K/Akt signaling pathway by targeting PTEN (34). The study provided a novel therapeutic RNA vehicle for glioma therapies.

Other cancers. Astrocyte elevated gene $1(A E G 1)$ is a direct target of miR-885-5p. Silencing AEG1 inhibited the expression of programmed death-ligand 1 and EGFR in HCC. Overexpression of miR-885-5p significantly inhibited cell migration, invasion, proliferation, angiogenesis and the EMT (86). Furthermore, AEGl was a direct target of miR-30e-5p in squamous cell carcinoma of the head and neck, which suppressed the migration of HUVECs, decreased the expression of VEGF and HGF, and was implicated in angiogenesis and metastasis (87). The miR signature may potentially be effective in diagnosis, prognosis and therapy in cancer. A previous study on gallbladder cancer validated $M A P 2 K 4$ as a target gene of miR-136 (88). miR-136 has been regarded as a tumor suppressor and oncogene that exerts its effects by targeting different genes in several cancer types. Overexpressed miR-136 inhibited angiogenesis and cell proliferation and promoted apoptosis in vitro and in vivo. Furthermore, the overexpression of dual-specificity mitogen-activated protein kinase kinase 4, and activation of the c-Jun N-terminal kinase signaling pathway, reversed the inhibitory effects of miR-136 on angiogenesis and tumorigenicity of gallbladder cancer cells (88). Overexpression of miR-136 may possess promising beneficial effects in therapeutic treatments for gallbladder cancer. Furthermore, miR-21 expression promoted the migration, invasion and angiogenic abilities of renal cell carcinoma cells by directly targeting the programmed cell death protein 4 (PDCD4)/c-Jun signaling pathway (89). The study illustrated the molecular mechanism underlying renal cell carcinoma progression and provided a promising target for miRs-based therapy.

\section{5. miRs as biomarkers in patients with cancer}

Current research demonstrates that miRs in blood or tissues may be used as potential biomarkers for tumor classification, diagnosis and disease progression monitoring (90). Several studies have identified numerous upregulated oncogenic miRs and downregulated tumor suppressor miRs in cancer (91-93). miRs participate in the intercellular communication process and may be used as diagnostic and prognostic biomarkers for cancer and as potential therapeutic targets. Consistent with these roles, certain miRs may function as oncogenes or tumor suppressors. miR expression profiling may yield pivotal biomarkers for cancer diagnostics. Therefore, herein, the miR biomarkers in body fluids for different types of cancer are summarized.

Exosomes, which contain multiple proteins, RNAs, and other molecules are secreted by a variety of viable cells. Certain miR biomarkers of cancer were detected in exosomes present in body fluids. Tumor-derived or tumor-related exosomes are important mediators of regulating tumor development and progression. Therefore, they may be utilized in the early diagnosis, treatment efficacy evaluation and prognosis prediction. miRs are involved in oncogenesis and demonstrate remarkable tissue specificity, a characteristic that may be used to detect cancer and improve tumor origin prediction $(94,95)$. With the development of detection methods, the majority of diagnostic expression profiling of miRs has been conducted using tumor tissue samples. However, several studies have reported the diagnostic and prognostic value of miRs in human body fluids (Table II, Fig. 3).

\section{Conclusions}

Angiogenesis is essential for tumor growth and metastasis. Several studies have made significant progress in investigating the regulatory actions of miRs in terms of tumor angiogenesis $(6,14,96)$. In the future, clinical breakthroughs are 
expected using miRs as predictive biomarkers and miRs-based anti-angiogenic therapeutic strategies; however, numerous challenges remain. Since a single miR may regulate angiogenesis by targeting multiple miRs, multi-target anti-angiogenesis drugs may form a novel therapeutic approach with broad prospects for antitumor treatment. However, miR-targeting approaches may affect normal and abnormal angiogenesis. Therefore, it is important to identify and target miRs that may distinguish angiogenic endothelial cells in the tumor vasculature from those in normal tissues $(7,97)$. This review aimed to improve the understanding of the mechanisms of miRs in tumor angiogenesis. This will guide further exploratory studies to understand the processes of the tumor-associated neovasculature and may contribute toward the development of miR-based therapies capable of delaying the progression of angiogenesis-related diseases.

\section{Acknowledgements}

Not applicable.

\section{Funding}

The present study was supported by Beijing Municipal Natural Science Foundation (grant no. 7214294).

\section{Availability of data and materials}

The data used to support the findings of this study are available from the corresponding author upon reasonable request.

\section{Authors' contributions}

QZ and WH conceived and designed the study. QZ drafted the manuscript and supported the funding. WH provided technical guidance and revised the paper. All authors read and approved the final manuscript. Data authentication is not applicable.

\section{Ethics approval and consent to participate}

Not applicable.

\section{Patient consent for publication}

Not applicable.

\section{Competing interests}

The authors declare that they have no competing interests.

\section{References}

1. Lagacé F, Ghazawi FM, Le M, Rahme E, Savin E, Zubarev A, Alakel A, Sasseville D, Moreau L, Meterissian S and Litvinov IV: Analysis of incidence, mortality trends, and geographic distribution of breast cancer patients in Canada. Breast Cancer Res Treat 178: 683-691, 2019.

2. Ruppert AS, Dixon JG, Salles G, Wall A, Cunningham D, Poeschel V, Haioun C, Tilly $\mathrm{H}$, Ghesquieres $\mathrm{H}$, Ziepert M, et al: International prognostic indices in diffuse large B-cell lymphoma: A comparison of IPI, R-IPI and NCCN-IPI. Blood 135: 2041-2048, 2020.
3. Li S, Xu HX, Wu CT, Wang WQ, Jin W, Gao HL, Li H, Zhang SR, $\mathrm{Xu}$ JZ, Qi ZH, et al: Angiogenesis in pancreatic cancer: Current research status and clinical implications. Angiogenesis 22: 15-36, 2019.

4. Orso F, Quirico L, Dettori D, Coppo R, Virga F, Ferreira LC, Paoletti C, Baruffaldi D, Penna E and Taverna D: Role of miRNAs in tumor and endothelial cell interactions during tumor progression. Semin Cancer Biol 60: 214-224, 2020.

5. Bisgin H, Gong B, Wang Y and Tong W: Evaluation of bioinformatics approaches for Next-Generation sequencing analysis of microRNAs with a toxicogenomics study design. Front Genet 9: 22, 2018.

6. Lee YS and Dutta A: MicroRNAs in cancer. Annu Rev Pathol 4: 199-227, 2009.

7. Wang Y, Wang L, Chen $\mathrm{C}$ and Chu X: New insights into the regulatory role of microRNA in tumor angiogenesis and clinical implications. Mol Cancer 17: 22, 2018.

8. Hansen TB: Detecting agotrons in ago CLIPseq Data. Methods Mol Biol 1823: 221-232, 2018.

9. Vishnoi A and Rani S: MiRNA biogenesis and regulation of diseases: An overview. Methods Mol Biol 1509: 1-10, 2017.

10. Denli AM, Tops BB, Plasterk RH, Ketting RF and Hannon GJ: Processing of primary microRNAs by the Microprocessor complex. Nature 432: 231-235, 2004

11. Cheng L, Li F, Jiang Y, Yu H, Xie C, Shi Y and Gong Q: Structural insights into a unique preference for 3' terminal guanine of mirtron in Drosophila TUTase tailor. Nucleic Acids Res 47: 495-508, 2019.

12. Michlewski G and Cáceres JF: Post-transcriptional control of miRNA biogenesis. RNA 25: 1-16, 2019.

13. Leung DW, Cachianes G, Kuang WJ, Goeddel DV and Ferrara N: Vascular endothelial growth factor is a secreted angiogenic mitogen. Science 246: 1306-1309, 1989.

14. Goradel NH, Mohammadi N, Haghi-Aminjan H, Farhood B, Negahdari B and Sahebkar A: Regulation of tumor angiogenesis by microRNAs: State of the art. J Cell Physiol 234: 1099-1110, 2019.

15. LiR, Qi Y, Jiang M,Zhang T, Wang H, Wang L and Han M: Primary tumor-secreted VEGF induces vascular hyperpermeability in premetastatic lung via the occludin phosphorylation/ubiquitination pathway. Mol Carcinog 58: 2316-2326, 2019.

16. Xu J, Xie L and Guo W: PDGF/PDGFR effects in osteosarcoma and the 'add-on' strategy. Clin Sarcoma Res 8: 15, 2018.

17. DeLisser HM, Christofidou-Solomidou M, Strieter RM, Burdick MD, Robinson CS, Wexler RS, Kerr JS, Garlanda C, Merwin JR, Madri JA and Albelda SM: Involvement of endothelial PECAM-1/CD31 in angiogenesis. Am J Pathol 151: 671-677, 1997.

18. Fang L, He Y, Liu Y, Ding H, Tong Y, Hu L, Wang C, Zhang Y, Zheng $X$ and Huang P: Adjustment of microvessel area by stromal area to improve survival prediction in non-small cell lung cancer. J Cancer 10: 3397-3406, 2019.

19. Hida K, Maishi N, Annan DA and Hida Y: Contribution of tumor endothelial cells in cancer progression. Int J Mol Sci 19: 1272, 2018.

20. Zhang Y, Zhao HJ, Xia XR, Diao FY, Ma X, Wang J, Gao L, Liu J, Gao C, Cui YG and Liu JY: Hypoxia-induced and HIF1 $\alpha$-VEGF-mediated tight junction dysfunction in choriocarcinoma cells: Implications for preeclampsia. Clin Chim Acta 489: 203-211, 2019.

21. Li L, Li JC, Yang H, Zhang X, Liu LL, Li Y, Zeng TT, Zhu YH, $\mathrm{Li} \mathrm{XD}, \mathrm{Li}$ Y, et al: Expansion of cancer stem cell pool initiates lung cancer recurrence before angiogenesis. Proc Natl Acad Sci USA 115: E8948-E8957, 2018.

22. Okamoto T, Usuda H, Tanaka T, Wada K and Shimaoka M: The functional implications of endothelial gap junctions and cellular mechanics in vascular angiogenesis. Cancers 11: 237, 2019.

23. Kalluri R and LeBleu VS: The biology, function, and biomedical applications of exosomes. Science 367: eaau6977, 2020.

24. Sun Z, Shi K, Yang S, Liu J, Zhou Q, Wang G, Song J, Li Z, Zhang $Z$ and Yuan W: Effect of exosomal miRNA on cancer biology and clinical applications. Mol Cancer 17: 147, 2018.

25. Tomasetti M, Lee W, Santarelli L and Neuzil J: Exosome-derived microRNAs in cancer metabolism: Possible implications in cancer diagnostics and therapy. Exp Mol Med 49: e285, 2017.

26. Hsu YL, Hung JY, Chang WA, Lin YS, Pan YC, Tsai PH, Wu CY and Kuo PL: Hypoxic lung cancer-secreted exosomal miR-23a increased angiogenesis and vascular permeability by targeting prolyl hydroxylase and tight junction protein ZO-1. Oncogene 36: 4929-4942, 2017. 
27. Zeng Z, Li Y, Pan Y, Lan X, Song F, Sun J, Zhou K, Liu X, Ren X, Wang F, et al: Cancer-derived exosomal miR-25-3p promotes pre-metastatic niche formation by inducing vascular permeability and angiogenesis. Nat Commun 9: 5395, 2018.

28. He L, Zhu W, Chen Q, Yuan Y, Wang Y, Wang J and Wu X: Ovarian cancer cell-secreted exosomal miR-205 promotes metastasis by inducing angiogenesis. Theranostics 9: 8206-8220, 2019.

29. Masoumi-Dehghi S, Babashah $\mathrm{S}$ and Sadeghizadeh $\mathrm{M}$ : MicroRNA-141-3p-containing small extracellular vesicles derived from epithelial ovarian cancer cells promote endothelial cell angiogenesis through activating the JAK/STAT3 and NF-кB signaling pathways. J Cell Commun Signal 14: 233-244, 2020.

30. Chen X, Mangala LS, Mooberry L, Bayraktar E, Dasari SK, Ma S Ivan C, Court KA, Rodriguez-Aguayo C, Bayraktar R, et al: Identifying and targeting angiogenesis-related microRNAs in ovarian cancer. Oncogene 38: 6095-6108, 2019.

31. Zhou Y, Ren H, Dai B, Li J, Shang L, Huang J and Shi X Hepatocellular carcinoma-derived exosomal miRNA-21 contributes to tumor progression by converting hepatocyte stellate cells to cancer-associated fibroblasts. J Exp Clin Cancer Res 37: 324, 2018 .

32. Zhao S, Li J, Zhang G, Wang Q, Wu C, Zhang Q, Wang H, Sun P, Xiang R and Yang S: Exosomal miR-451a functions as a tumo suppressor in hepatocellular carcinoma by targeting LPIN1. Cell Physiol Biochem 53: 19-35, 2019.

33. Chen X, Yang F, Zhang T, Wang W, Xi W, Li Y, Zhang D, Huo Y, Zhang J, Yang A and Wang T: MiR-9 promotes tumorigenesis and angiogenesis and is activated by MYC and OCT4 in human glioma. J Exp Clin Cancer Res 38: 99, 2019.

34. Wang ZF, Liao F, Wu H and Dai J: Glioma stem cells-derived exosomal miR-26a promotes angiogenesis of microvessel endothelial cells in glioma. J Exp Clin Cancer Res 38: 201, 2019.

35. Bai M, Li J, Yang H, Zhang H, Zhou Z, Deng T, Zhu K, Ning T, Fan Q, Ying G and Ba Y: MiR-135b delivered by gastric tumor exosomes inhibits FOXO1 expression in endothelial cells and promotes angiogenesis. Mol Ther 27: 1772-1783, 2019.

36. Lawson J, Dickman C, Towle R, Jabalee J, Javer A and Garnis C: Extracellular vesicle secretion of miR-142-3p from lung adenocarcinoma cells induces tumor promoting changes in the stroma through cell-cell communication. Mol Carcinog 58: 376-387, 2019.

37. Yin Z, Ma T, Huang B, Lin L, Zhou Y, Yan J, Zou Y and Chen S: Macrophage-derived exosomal microRNA-501-3p promotes progression of pancreatic ductal adenocarcinoma through the TGFBR3-mediated TGF- $\beta$ signaling pathway. J Exp Clin Cancer Res 38: 310, 2019.

38. Yamada NO, Heishima K, Akao Y and Senda T: Extracellular vesicles containing MicroRNA-92a-3p facilitate partial Endothelial-Mesenchymal transition and angiogenesis in endothelial cells. Int J Mol Sci 20: 4406, 2019.

39. $\mathrm{Hu} \mathrm{HY}$, Yu CH, Zhang HH, Zhang SZ, Yu WY, Yang Y and Chen Q: Exosomal miR-1229 derived from colorectal cancer cells promotes angiogenesis by targeting HIPK2. Int J Biol Macromol 132: 470-477, 2019.

40. Bazzoni G and Dejana E: Endothelial cell-to-cell junctions: Molecular organization and role in vascular homeostasis. Physio Rev 84: 869-901, 2004

41. Lesage J, Suarez-Carmona M, Neyrinck-Leglantier D, Grelet S, Blacher S, Hunziker W, Birembaut P, Noël A, Nawrocki-Raby B, Gilles $\mathrm{C}$ and Polette M: Zonula occludens-1/NF- $\mathrm{kB} / \mathrm{CXCL8}$ A new regulatory axis for tumor angiogenesis. FASEB J 31: 1678-1688, 2017

42. Bhat AA, Uppada S, Achkar IW, Hashem S, Yadav SK Shanmugakonar M, Al-Naemi HA, Haris M and Uddin S: Tight junction proteins and signaling pathways in cancer and inflammation: A functional crosstalk. Front Physiol 9: 1942, 2019.

43. Chao YC, Pan SH, Yang SC, Yu SL, Che TF, Lin CW, Tsai MS, Chang GC, Wu CH, Wu YY, et al: Claudin-1 is a metastasis suppressor and correlates with clinical outcome in lung adenocarcinoma. Am J Respir Crit Care Med 179: 123-133, 2009.

44. Zhao L, Wang P, Liu Y, Ma J and Xue Y: MiR-34c regulates the permeability of blood-tumor barrier via MAZ-mediated expression changes of ZO-1, occludin, and claudin-5. J Cell Physiol 230: 716-731, 2015.

45. Tornavaca O, Chia M, Dufton N, Almagro LO, Conway DE, Randi AM, Schwartz MA, Matter K and Balda MS: ZO-1 controls endothelial adherens junctions, cell-cell tension, angiogenesis, and barrier formation. J Cell Biol 208: 821-838, 2015.
46. Wu T, Hu H, Zhang T, Jiang L, Li X, Liu S, Zheng C, Yan G, Chen W, Ning Y, et al: MiR-25 promotes cell proliferation, migration, and invasion of Non-Small-Cell lung cancer by targeting the LATS2/YAP signaling pathway. Oxid Med Cell Longev 2019: 9719723, 2019

47. Liu B and Sun X: MiR-25 promotes invasion of human non-small cell lung cancer via CDH1. Bioengineered 10: 271-281, 2019.

48. Xu FX, Su YL, Zhang H, Kong JY, Yu H and Qian BY: Prognostic implications for high expression of MiR-25 in lung adenocarcinomas of female non-smokers. Asian Pac J Cancer Prev 15: 1197-1203, 2014.

49. Zhou W, Fong MY, Min Y, Somlo G, Liu L, Palomares MR, Yu Y, Chow A, O'Connor ST, Chin AR, et al: Cancer-secreted miR-105 destroys vascular endothelial barriers to promote metastasis. Cancer Cell 25: 501-515, 2014.

50. Zhang L, Shen J, Cheng J and Fan X: MicroRNA-21 regulates intestinal epithelial tight junction permeability. Cell Biochem Funct 33: 235-240, 2015.

51. Cho HS, Han TS, Hur K and Ban HS: The roles of Hypoxia-inducible factors and non-coding RNAs in gastrointestinal cancer. Genes (Basel) 10: 1008, 2019.

52. Salinas-Vera YM, Marchat LA, Gallardo-Rincón D, Ruiz-García E, Astudillo-De La Vega H, Echavarría-Zepeda R and López-Camarillo C: AngiomiRs: MicroRNAs driving angiogenesis in cancer (Review). Int J Mol Med 43: 657-670, 2019.

53. Park JE, Dutta B, Tse SW, Gupta N, Tan CF, Low JK, Yeoh KW, Kon OL, Tam JP and Sze SK: Hypoxia-induced tumor exosomes promote M2-like macrophage polarization of infiltrating myeloid cells and microRNA-mediated metabolic shift. Oncogene 38: 5158-5173, 2019

54. Ren W, Hou J, Yang C, Wang H, Wu S, Wu Y, Zhao X and $\mathrm{Lu} \mathrm{C}$ : Extracellular vesicles secreted by hypoxia pre-challenged mesenchymal stem cells promote non-small cell lung cancer cell growth and mobility as well as macrophage M2 polarization via miR-21-5p delivery. J Exp Clin Cancer Res 38: 62, 2019.

55. Zhang S, Zhang R, Xu R, Shang J, He H and Yang Q: MicroRNA-574-5p in gastric cancer cells promotes angiogenesis by targeting protein tyrosine phosphatase non-receptor type 3 (PTPN3). Gene 733: 144383, 2020

56. Yu P, Fan S, Huang L, Yang L and Du Y: MIR210 as a potential molecular target to block invasion and metastasis of gastric cancer. Med Hypotheses 84: 209-212, 2015.

57. Chen F, Chen J, Yang L, Liu J, Zhang X, Zhang Y, Tu Q, Yin D, Lin D, Wong PP, et al: Extracellular vesicle-packaged HIF-1 $\alpha$-stabilizing lncRNA from tumour-associated macrophages regulates aerobic glycolysis of breast cancer cells. Nat Cell Biol 21: 498-510, 2019.

58. Liu L, Wang Y, Bai R, Yang K and Tian Z: MiR-186 inhibited aerobic glycolysis in gastric cancer via HIF-1 $\alpha$ regulation. Oncogenesis 6: e318, 2017.

59. Shivdasani RA: MicroRNAs: Regulators of gene expression and cell differentiation. Blood 108: 3646-3653, 2006.

60. Bielenberg DR and Zetter BR: The contribution of angiogenesis to the process of metastasis. Cancer J 21: 267-273, 2015.

61. Landskroner-Eiger S, Moneke I and Sessa WC: MiRNAs as modulators of angiogenesis. Cold Spring Harb Perspect Med 3: a006643, 2013.

62. Dimova I, Popivanov G and Djonov V: Angiogenesis in cancer-general pathways and their therapeutic implications. J BUON 19: 15-21, 2014.

63. Chen X, Xu X, Pan B, Zeng K, Xu M, Liu X, He B, Pan Y, Sun H and Wang S: MiR-150-5p suppresses tumor progression by targeting VEGFA in colorectal cancer. Aging (Albany NY) 10: 3421-3437, 2018

64. Mao Z, Xu B, He L and Zhang G: PVT1 promotes angiogenesis by regulating miR-29c/Vascular endothelial growth factor (VEGF) signaling pathway in non-small-cell lung cancer (NSCLC). Med Sci Monit 25: 5418-5425, 2019.

65. Yang F, Shao C, Wei K, Jing X, Qin Z, Shi Y, Shu Y and Shen H: MiR-942 promotes tumor migration, invasion, and angiogenesis by regulating EMT via BARX2 in non-small-cell lung cancer. J Cell Physiol 234: 23596-23607, 2019.

66. Gao LM, Zheng Y, Wang P, Zheng L, Zhang WL, Di Y, Chen LL, Yin XB, Tian Q, Shi SS and Xu SF: Tumor-suppressive effects of microRNA-181d-5p on non-small-cell lung cancer through the CDKN3-mediated Akt signaling pathway in vivo and in vitro. Am J Physiol Lung Cell Mol Physiol 316: L918-L933, 2019. 
67. Zhang Y, Chen Z, Feng L, Jiang P, Li X and Wang X: Ionizing Radiation-inducible microRNA-21 induces angiogenesis by directly targeting PTEN. Asian Pac J Cancer Prev 20: 1587-1593, 2019.

68. Liu H, Chen Y, Li Y, Li C, Qin T, Bai M, Zhang Z, Jia R, Su Y and Wang C: MiR-195 suppresses metastasis and angiogenesis of squamous cell lung cancer by inhibiting the expression of VEGF. Mol Med Rep 20: 2625-2632, 2019.

69. Hong Z, Hong C, Ma B, Wang Q, Zhang X, Li L, Wang C and Chen D: MicroRNA-126-3p inhibits the proliferation, migration, invasion, and angiogenesis of triple-negative breast cancer cells by targeting RGS3. Oncol Rep 42: 1569-1579, 2019.

70. Alhasan L: MiR-126 modulates angiogenesis in breast cancer by targeting VEGF-A-mRNA. Asian Pac J Cancer Prev 20: 193-197, 2019.

71. Zhao Z, Li L, Du P, Ma L, Zhang W, Zheng L, Lan B, Zhang B, Ma F, Xu B, et al: Transcriptional Downregulation of miR-4306 serves as a new therapeutic target for triple negative breast cancer. Theranostics 9: 1401-1416, 2019.

72. Hunter S, Nault B, Ugwuagbo KC, Maiti S and Majumder M: Mir526b and Mir655 promote tumour associated angiogenesis and lymphangiogenesis in breast cancer. Cancers (Basel) 11: 938, 2019 .

73. Lin X, Qiu W, Xiao Y, Ma J, Xu F, Zhang K, Gao Y, Chen Q, Li Y, Li H and Qian A: MiR-199b-5p suppresses tumor angiogenesis mediated by vascular endothelial cells in breast cancer by targeting ALK1. Front Genet 10: 1397, 2019.

74. Chen X, Zeng K, Xu M, Liu X, Hu X, Xu T, He B, Pan Y, Sun H and Wang S: P53-induced miR-1249 inhibits tumor growth, metastasis, and angiogenesis by targeting VEGFA and HMGA2. Cell Death Dis 10: 131, 2019

75. Lin $\mathrm{M}$, Zhang $\mathrm{Z}$, Gao $\mathrm{M}$, $\mathrm{Yu} \mathrm{H}$, Sheng $\mathrm{H}$ and Huang $\mathrm{J}$ : MicroRNA-193a-3p suppresses the colorectal cancer cell proliferation and progression through downregulating the PLAU expression. Cancer Manag Res 11: 5353-5363, 2019.

76. Fang Y, Sun B, Wang J and Wang Y: MiR-622 inhibits angiogenesis by suppressing the CXCR4-VEGFA axis in colorectal cancer. Gene 699: 37-42, 2019.

77. Fan X, Liu M, Tang H, Leng D, Hu S, Lu R, Wan W and Yuan S: MicroRNA-7 exerts antiangiogenic effect on colorectal cancer via ERK signaling. J Surg Res 240: 48-59, 2019.

78. Chen P, Guo H, Wu X, Li J, Duan X, Ba Q and Wang H: Epigenetic silencing of microRNA-204 by Helicobacter pylori augments the $\mathrm{NF}-\kappa \mathrm{B}$ signaling pathway in gastric cancer development and progression. Carcinogenesis 41: 430-441, 2020.

79. Shi Y, Huang X, Chen G, Wang Y, Liu Y, Xu W, Tang S, Guleng B, Liu J and Ren J: MiR-632 promotes gastric cancer progression by accelerating angiogenesis in a TFF1-dependent manner. BMC Cancer 19: 14, 2019.

80. Dai J, Wei R, Zhang P and Kong B: Overexpression of microRNA-195-5p reduces cisplatin resistance and angiogenesis in ovarian cancer by inhibiting the PSAT1-dependent GSK3 $\beta /$ $\beta$-catenin signaling pathway. J Transl Med 17: 190, 2019.

81. Lu J, Xu Y, Wei X, Zhao Z, Xue J and Liu P: Emodin inhibits the epithelial to mesenchymal transition of epithelial ovarian cancer cells via ILK/GSK-3 $\beta /$ Slug signaling pathway. Biomed Res Int 2016: 6253280, 2016.

82. Salinas-Vera YM, Gallardo-Rincón D, García-Vázquez R, Hernández-de la Cruz ON, Marchat LA, González-Barrios JA, Ruíz-García E, Vázquez-Calzada C, Contreras-Sanzón E, Resendiz-Hernández $\mathrm{M}$, et al: HypoxamiRs profiling identify miR-745 as a regulator of the early stages of vasculogenic mimicry in SKOV3 ovarian cancer cells. Front Oncol 9: 381, 2019.

83. Mu HQ, He YH, Wang SB, Yang S, Wang YJ, Nan CJ, Bao YF, Xie QP and Chen YH: MiR-130b/TNF- $\alpha / \mathrm{NF}-\kappa \mathrm{B} / \mathrm{VEGFA}$ loop inhibits prostate cancer angiogenesis. Clin Transl Oncol 22: 111-121, 2020.

84. Zhang P, Yang X, Wang L, Zhang D, Luo Q and Wang B: Overexpressing miR-335 inhibits DU145 cell proliferation by targeting early growth response 3 in prostate cancer. Int J Oncol 54: 1981-1994, 2019.

85. He Q, Zhao L, Liu X, Zheng J, Liu Y, Liu L, Ma J, Cai H, Li Z and Xue Y: MOV10 binding circ-DICER1 regulates the angiogenesis of glioma via miR-103a-3p/miR-382-5p mediated ZIC4 expression change. J Exp Clin Cancer Res 38: 9, 2019.

86. Li C, Wang $X$ and Song Q: MicroRNA 885-5p inhibits hepatocellular carcinoma metastasis by repressing AEG1. Onco Targets Ther 13: 981-988, 2020.
87. Zhang S, Li G, Liu C, Lu S, Jing Q, Chen X, Zheng H, Ma H, Zhang D, Ren S, et al: MiR-30e-5p represses angiogenesis and metastasis by directly targeting AEG-1 in squamous cell carcinoma of the head and neck. Cancer Sci 111: 356-368, 2020.

88. Niu J, Li Z and Li F: Overexpressed microRNA-136 works as a cancer suppressor in gallbladder cancer through suppression of JNK signaling pathway via inhibition of MAP2K4. Am J Physiol Gastrointest Liver Physiol 317: G670-G681, 2019.

89. Fan B, Jin Y, Zhang H, Zhao R, Sun M, Sun M, Yuan X, Wang W, Wang X, Chen Z, et al: MicroRNA-21 contributes to renal cell carcinoma cell invasiveness and angiogenesis via the PDCD4/c-Jun (AP-1) signalling pathway. Int J Oncol 56: 178-192, 2020

90. Wang H, Peng R, Wang J, Qin Z and Xue L: Circulating microRNAs as potential cancer biomarkers: The advantage and disadvantage. Clin Epigenetics 10: 59, 2018.

91. Ali Syeda Z, Langden SSS, Munkhzul C, Lee M and Song SJ: Regulatory mechanism of MicroRNA expression in cancer. Int J Mol Sci 21: 1723, 2020.

92. Hammouz RY, Kołat D, Kałuzińska Ż, Płuciennik E and Bednarek AK: MicroRNAs: Their role in metastasis, angiogenesis, and the potential for biomarker utility in bladder carcinomas. Cancers (Basel) 13: 891, 2021.

93. Tipanee J, Di Matteo M, Tulalamba W, Samara-Kuko E, Keirsse J, Van Ginderachter JA, Chuah MK and VandenDriessche T: Validation of miR-20a as a tumor suppressor gene in liver carcinoma using hepatocyte-specific hyperactive piggyBac transposons. Mol Ther Nucleic Acids 19: 1309-1329, 2020

94. Rosenfeld N, Aharonov R, Meiri E, Rosenwald S, Spector Y, Zepeniuk M, Benjamin H, Shabes N, Tabak S, Levy A, et al: MicroRNAs accurately identify cancer tissue origin. Nat Biotechnol 26: 462-469, 2008.

95. Søkilde R, Vincent M, Møller AK, Hansen A, Høiby PE, Blondal T, Nielsen BS, Daugaard G, Møller S and Litman T: Efficient identification of miRNAs for classification of tumor origin. J Mol Diagn 16: 106-115, 2014.

96. Yang Y, Guo Z, Chen W, Wang X, Cao M, Han X, Zhang K, Teng B, Cao J, Wu W, et al: M2 macrophage-derived exosomes promote angiogenesis and growth of pancreatic ductal adenocarcinoma by targeting E2F2. Mol Ther 29: 1226-1238, 2021.

97. Caporali A and Emanueli C: MicroRNA regulation in angiogenesis. Vascul Pharmacol 55: 79-86, 2011

98.Szajnik M, Czystowska-Kuźmicz M, Elishaev E and Whiteside TL: Biological markers of prognosis, response to therapy and outcome in ovarian carcinoma. Expert Rev Mol Diagn 16: 811-826, 2016.

99. Taylor DD and Gercel-Taylor C: MicroRNA signatures of tumor-derived exosomes as diagnostic biomarkers of ovarian cancer. Gynecol Oncol 110: 13-21, 2008.

100. Qattan A, Intabli H, Alkhayal W, Eltabache C, Tweigieri T and Amer SB: Robust expression of tumor suppressor miRNA's let-7 and miR-195 detected in plasma of Saudi female breast cancer patients. BMC Cancer 17: 799, 2017.

101. Hu X, Fan J, Duan B, Zhang H, He Y, Duan P and Li X: Single-molecule catalytic hairpin assembly for rapid and direct quantification of circulating miRNA biomarkers. Anal Chim Acta 1042: 109-115, 2018.

102. Tsujiura M, Ichikawa D, Komatsu S, Shiozaki A, Takeshita H, Kosuga T, Konishi H, Morimura R, Deguchi K, Fujiwara H, et al: Circulating microRNAs in plasma of patients with gastric cancers. Br J Cancer 102: 1174-1179, 2010.

103.Zhou Q, Liu J, Quan J, Liu W, Tan H and Li W: MicroRNAs as potential biomarkers for the diagnosis of glioma: A systematic review and meta-analysis. Cancer Sci 109: 2651-2659, 2018.

104. Hu Z, Chen X, Zhao Y, Tian T, Jin G, Shu Y, Chen Y, Xu L, Zen K, Zhang C and Shen H: Serum microRNA signatures identified in a genome-wide serum microRNA expression profiling predict survival of non-small-cell lung cancer. J Clin Oncol 28: $1721-1726,2010$

105. Rabinowits G, Gerçel-Taylor C, Day JM, Taylor DD and Kloecker GH: Exosomal microRNA: A diagnostic marker for lung cancer. Clin Lung Cancer 10: 42-46, 2009.

106. Yamamoto Y, Kosaka N, Tanaka M, Koizumi F, Kanai Y, Mizutani T, Murakami Y, Kuroda M, Miyajima A, Kato T and Ochiya T: MicroRNA-500 as a potential diagnostic marker for hepatocellular carcinoma. Biomarkers 14: 529-538, 2009. 
107. Sabo AA, Birolo G, Naccarati A, Dragomir MP, Aneli S, Allione A, Oderda M, Allasia M, Gontero P, Sacerdote C, et al: Small Non-Coding RNA profiling in plasma extracellular vesicles of bladder cancer patients by next-generation sequencing: Expression levels of miR-126-3p and piR-5936 increase with higher histologic grades. Cancers (Basel) 12: 1507, 2020.

108. Xie F, Li Y, Wang M, Huang C, Tao D, Zheng F, Zhang H, Zeng F, Xiao X and Jiang G: Circular RNA BCRC-3 suppresses bladder cancer proliferation through $\mathrm{miR}-182-5 \mathrm{p} / \mathrm{p} 27$ axis. Mol Cancer 17: 144, 2018.

109. Tanaka Y, Kamohara H, Kinoshita K, Kurashige J, Ishimoto T, Iwatsuki M, Watanabe $M$ and Baba $\mathrm{H}$ : Clinical impact of serum exosomal microRNA-21 as a clinical biomarker in human esophageal squamous cell carcinoma. Cancer 119: 1159-1167, 2013.

110. Liu J, Sun H, Wang X, Yu Q, Li S, Yu X and Gong W: Increased exosomal microRNA-21 and microRNA-146a levels in the cervicovaginal lavage specimens of patients with cervical cancer. Int J Mol Sci 15: 758-773, 2014.
111. Park NJ, Zhou H, Elashoff D, Henson BS, Kastratovic DA, Abemayor E and Wong DT: Salivary microRNA: Discovery, characterization, and clinical utility for oral cancer detection. Clin Cancer Res 15: 5473-5477, 2009.

112. El-Daly SM, Morsy SM, Medhat D, El-Bana MA, Latif YA, Omara EA, Awadallah JR and Gamal-Eldeen AM: The diagnostic efficacy of circulating miRNAs in monitoring the early development of colitis-induced colorectal cancer. J Cell Biochem 120: 16668-16680, 2019.

113. Ng EK, Chong WW, Jin H, Lam EK, Shin VY, Yu J, Poon TC, Ng SS and Sung JJ: Differential expression of microRNAs in plasma of patients with colorectal cancer: A potential marker for colorectal cancer screening. Gut 58: 1375-1381, 2009.

This work is licensed under a Creative Commons

Attribution-NonCommercial-NoDerivatives 4.0 International (CC BY-NC-ND 4.0) License. 